\title{
Design of Photovoltaic Water Pumping System as an Alternative to Grid Network in Oman
}

\author{
A. Al-Badi and H. Yousef \\ Department of Electrical and Computer Engineering \\ College of Engineering, Sultan Qaboos University \\ Phone/Fax number:+9682414100, e-mail: albadi@squ.edu.om, hyousef@squ.edu.om
}

\begin{abstract}
The agriculture areas in Oman is scattered, thus providing electric power from the grid will be costly. Oman is blessed with high level of solar radiations with a yearly average of $5 \mathrm{kWh} / \mathrm{m}^{2} /$ day in most locations. Thus, using photovoltaic as an alternative power source for water pumping is considered one of the promising solutions since the cost of the photovoltaic (PV) module drops dramatically in recent years. The proposed system consists of PV, inverter, AC motor, centrifugal pump and storage tank. This paper presents system design and compares the costeffectiveness and the Present Value Cost (PVC) for the economic evaluation of power supply for pumping systems in remote areas using two different energy supply systems, namely, photovoltaic systems and grid network. A case study in northern part of Oman is selected to analyze the two pumping systems, which are designed to supply water for irrigation and drinking.
\end{abstract}

\section{Key words}

PV modules, solar radiation, water pumping system, Electrical Grid, Present Value of Cost.

\section{Introduction}

High level of solar energy density is available in almost all areas of Oman. It is positioned between Latitudes $16^{\circ} 40^{\prime}$ and $26^{\circ} 20^{\prime}$ North and Longitudes $51^{\circ} 50^{\prime}$ and $59^{\circ} 40^{\prime}$ East. The high ratio of sky clearness, at about 342 days per year, and the geographical location of Oman result in a huge potential for solar electricity generation. Although the potential of renewable energy in Oman, particularly solar energy, is very promising, however solar energy applications are limited to street lighting, traffic lights, telephone in remote areas, cathodic protection of pipelines and providing part of energy to some buildings. The desert and northern parts of Oman areas have the highest solar energy density while the coastal areas in the southern part have the lowest solar energy density and relatively high wind speed [1-5].

Diesel pumps have traditionally been used in Oman to pump water for irrigation, livestock and drinking. Today most of these are replaced by electrical pumps, which are connected to the grid network. The contribution of the consumer to the extension of the electric distribution to his/her farm is minimum, but he/she has to pay for the electrical cable from the distribution system up to the farm. Furthermore, there are some farms which are far away from the distribution system, thus using photovoltaic for water pumping is an attractive solution with the declining price of the PV system.

In reference [6], a PV water pumping system for Sohar city, Oman, has been designed and assessed. The results have shown that the cost of PV system energy is 0.309 $\mathrm{USD} / \mathrm{kWh}$ in comparison with the cost of diesel engine energy which is $0.79 \mathrm{USD} / \mathrm{kWh}$. References [7-8] show that solar water pumping systems are suitable for drinking water and minor irrigation applications in areas where cheaper sources of energy are not readily available. Reference [9] shows that the PV water pumping systems can be more cost effective than diesel engines to energize pumping systems in Jordan Badia. A model to characterize the motor-pumps subsystems used in PV pumping installations is discussed in [10]. The model expresses the water flow output $(\mathrm{Q})$ directly as a function of the electrical power input $(\mathrm{P})$ to the motorpump, for different total heads.

This paper presents and discusses the PV system sizing to be mainly used for farm irrigation. An existing farm located in the northern part of Oman is considered as a case study. The farm uses a motor water-pump fed from local electrical distribution system. The size of the farm is 4.5 acres and is irrigated by several methods based on the type of crops (drip, flood and sprinkler). The farm has livestock and provides water supply to three houses. The depth of the well is $17 \mathrm{~m}$ and the flow rate is around 1000 liter/minute. Economic analysis will be performed for a PV pumping system as an alternative to the electrical network.

\section{Photovoltaic System sizing and Components}

A. Pumping System sizing

\section{1) The Pump}

Water pumps may be classified into three types according to their applications: surface, submersible, and floating water pumps. The surface water pump is placed outside the well. This type is efficient if used to draw water from 
shallow wells. A submersible pump is submersed in the water and draws water from deep wells. A floating water pump is placed on the water surface and draws water from reservoirs with adjusting height ability. The pumps are categorized according to their pumping principle:

-centrifugal pumps, where liquid is sucked by the impeller and the centrifugal force directs the liquid to the outlet as the impeller rotates. The liquid leaves with a higher pressure and velocity than it had when it entered the pump.

-screw pumps, where a screw movement traps the water in the suction side of the pump casing and forces it to the outlet.

-Piston Pump, where water pumping depends on piston movement and two valves. While the piston moves, it draws water into a chamber using an inlet valve and expels it to the outlet using the outlet valve.

The selection of an appropriate pump in a solar water pumping system depends on water requirement and water height. The sizing of a PV water-pumping system depends on expected hydraulic load. The typical head consists of a static and a dynamic components.

The static head represents the vertical distance from the water surface level to the point of discharge as shown in Figure $1(\mathrm{~A}+\mathrm{B})$. During the pumping process, the water level drops (drawdown), this is represented by height $C$ in Figure 1. Furthermore, there is another component that represents the frictional losses owing to pumping water through the pipe. Reduction of these losses is possible by oversizing the pipe, eliminating bends and reducing the flow rate. Thus, the total dynamic head is the sum of the static head, the drawdown distance and the distance that represents the friction losses in the pipe (total dynamic head $=\mathrm{A}+\mathrm{B}+\mathrm{C}+$ friction losses) [11].

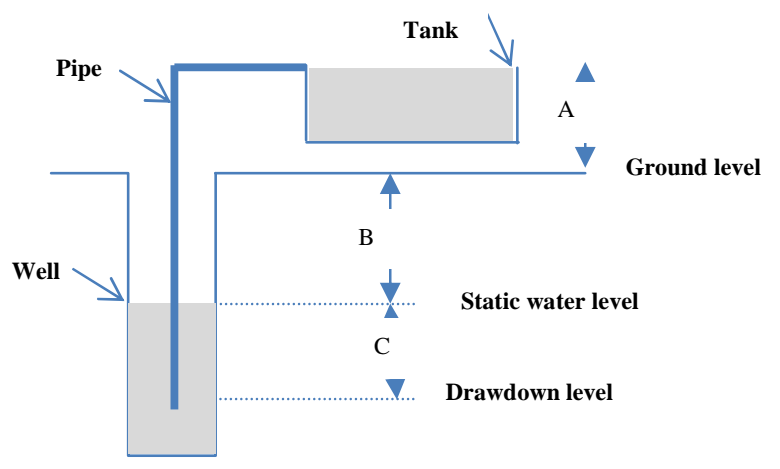

Figure 1: The typical heads of the water pump

\section{2) The Pump Motor}

There are several types of electrical motors that can be utilized to run the pump such as AC, DC, permanent magnet, brushed, brushless, synchronous and asynchronous, variable reluctance, and many more. If DC motor is used then the PV array could be directly connected to the motor, however the brushes of the motor needs to be changed regularly. Using $\mathrm{AC}$ motor will require the use of an inverter between the PV and the motor. Normally, the motor and pump are built-in together for submersible and floating systems. In the surface system, it is possible to select the pump and motor separately and evaluate their performance [12].

The size of the water pump and the hydraulic system is calculated based on the following equation [13]:

$$
P=\frac{\rho g(h+\Delta H) Q}{\eta_{b} \eta_{e}}
$$

where,

$P=$ Pumping power $(\mathrm{W})$

$\boldsymbol{\rho}=$ Water density $\left(\mathrm{kg} / \mathrm{m}^{3}\right)$

$\boldsymbol{g}=$ Acceleration due to gravity $\left(9.81 \mathrm{~m} / \mathrm{s}^{2}\right)$

$\boldsymbol{h}=$ Total pumping head (m)

$\Delta \boldsymbol{H}=$ Hydraulic losses $(\mathrm{m})$

$\boldsymbol{Q}=$ Water flow rate $\left(\mathrm{m}^{3} / \mathrm{s}\right)$

$\boldsymbol{\eta}_{\boldsymbol{b}}=$ Efficiency of the pump

$\boldsymbol{\eta}_{\boldsymbol{e}}=$ Efficiency of the motor

The hydraulic energy required per day $(\mathrm{kWh})$ is calculated based on the following equation [14]:

$$
E_{h}=\rho g h V=\eta_{s} E_{p v}
$$

where $\mathbf{V}$ is the volume of water required in $\mathrm{m}^{3} / \mathrm{day}, \boldsymbol{\eta}_{\mathbf{s}}$ is the subsystem (motor, pump and any inverter) efficiency, and $\mathbf{E}_{\mathbf{p v}}$ is the PV energy

\section{B. Photovoltaic system sizing}

The schematic diagram for a typical PV pumping system is shown in Figure 2.

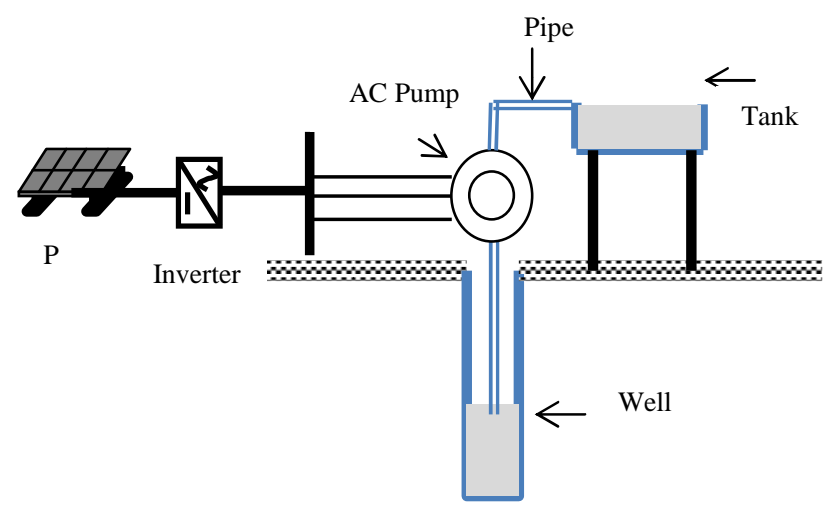

Figure 2: Schematic diagram for a typical PV pumping system 
A stand-alone PV water pumping system sizing involves finding the required size of the PV to meet the expected load requirements. It is standard to apply a safety factor for the PV size to compensate for the power losses owing to aging, heat, dust, etc. [15].

The power of a PV array can be calculated based on solar radiation energy [13] as:

$$
P=A_{p v} G_{r} \eta_{r}
$$

where:

$\boldsymbol{P}=$ photovoltaic power $(\mathrm{W})$

$\boldsymbol{A}_{\boldsymbol{p} \boldsymbol{v}}=$ effective area of $\mathrm{PV}\left(\mathrm{m}^{2}\right)$

$\boldsymbol{G}_{\boldsymbol{r}}=$ solar radiation at reference temperature $\left(1000 \mathrm{~W} / \mathrm{m}^{2}\right)$

$\boldsymbol{\eta}_{\boldsymbol{r}}=$ Efficiency of PV at reference temperature $\left(25 \mathrm{C}^{\circ}\right)$

The daily energy output of the PV can be calculated from [13]:

$$
\boldsymbol{E}_{p v}=\boldsymbol{A}_{p v} \boldsymbol{G}_{T} \boldsymbol{\eta}_{p v}
$$

where $\boldsymbol{G}_{\boldsymbol{T}}$ is the daily solar radiation on PV surface $\left(\mathrm{kWh} / \mathrm{m}^{2}\right)$, and $\boldsymbol{\eta}_{\boldsymbol{p} v}$ is the efficiency of the PV under the operating condition.

The area of the PV can be calculated from (2) and (4) as follows:

$$
A_{p v}=\frac{\rho g h V}{G_{T} \eta_{s} \eta_{p v}}
$$

Thus, the PV array size required in $\mathrm{kW}$ is

$$
P_{p v}=\frac{E_{h}}{G_{T} \times F \times E}
$$

where $\boldsymbol{F}$ is the PV mismatch factor (a safety factor for real panel performance) with typical values range between $0.85-0.9$ and $\boldsymbol{E}$ is the daily subsystem efficiency which typically has a value range between 0.2 to 0.6 [13].

To compensate for the power losses due to heat, dust and aging, the selected array size is taken as $1.2 \boldsymbol{P}_{p v}$.

The overall efficiency of the PV water pump can be found from the output hydraulic energy and input solar radiation energy as

$$
\eta_{o}=\frac{E_{h}}{E_{\text {in }}}=\frac{\rho g h V}{G_{T} A_{p v}}
$$

\section{Results and Discussion}

\section{A. Case study}

The case study farm selected in this paper is located in Saham that is around $200 \mathrm{~km}$ from Muscat, Oman. The global solar radiation values for 25 locations in Oman were discussed in reference [1]. The average value for global solar radiation in Sohar (close to Saham) is 5.6 $\mathrm{kWh} / \mathrm{m}^{2} /$ day.

The size of the farm is 4.5 acres, and is irrigated by several methods based on the type of crops (drip, flood and sprinkler). The farm has livestock and provides water supply to three houses. The pump is of centrifugal type and run by $11 \mathrm{~kW}$ induction motor fed directly from grid. The depth of the well is $17 \mathrm{~m}$, the static level is $13.5 \mathrm{~m}$, the drawdown level is $2 \mathrm{~m}$, and the flow rate is around 1000 liter/minute. The picture of the existing system is shown in Figure 3.

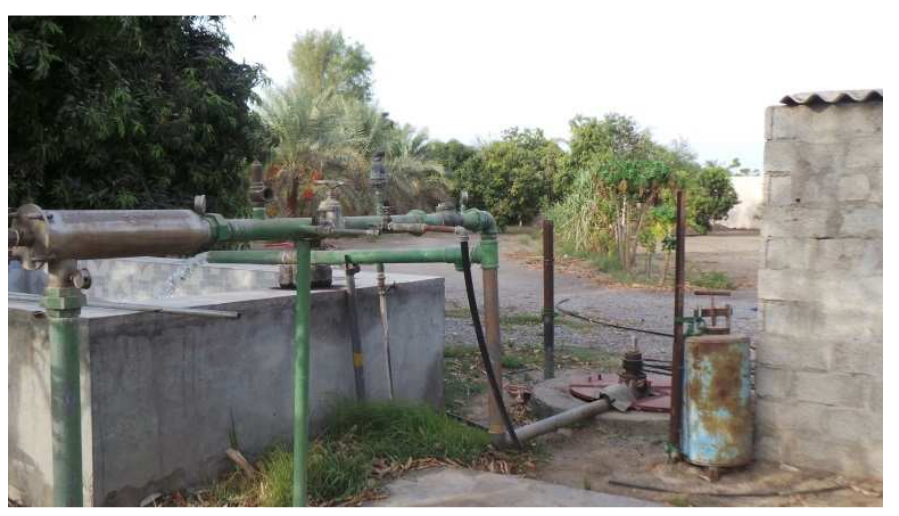

Figure 3: The picture of the existing system

In order to optimize the sizing of the PV, the hydraulic energy required per day should be determined. The parameter of the system is presented in Table I. Using these system parameters in the previous equations, the size of the PV array is found to be $5.8 \mathrm{~kW}$. To compensate for the power losses due to heat, dust and aging, the selected array size is calculated as $1.2(5.8)=7$ $\mathrm{kW}$.

The PV modules are available in different sizes, using $250 \mathrm{~W}$ module with area of $1.63 \mathrm{~m}^{2}$, thus the total required area will be $46 \mathrm{~m}^{2}$ (28 modules). The specifications of the selected module are presented in Table II [16].

Table I. - System parameters

\begin{tabular}{|c|c|}
\hline Parameter & Value \\
\hline $\mathrm{h}$ & $18 \mathrm{~m}$ \\
\hline $\mathrm{G}$ & $5.6 \mathrm{kWh} / \mathrm{m}^{2} /$ day \\
\hline $\mathrm{g}$ & $9.81 \mathrm{~m} / \mathrm{s}^{2}$ \\
\hline $\boldsymbol{\rho}$ & $1000 \mathrm{~kg} / \mathrm{m}^{3}$ \\
\hline $\mathbf{Q}$ & 1000 liter $/ \mathrm{minute}^{2}$ \\
\hline $\boldsymbol{\eta}_{\mathbf{p v}}$ & $13 \%$ \\
\hline $\boldsymbol{\eta}_{\mathbf{s}}$ & $50 \%$ \\
\hline $\mathrm{V}$ & $300 \mathrm{~m}^{3} /$ day \\
\hline $\mathrm{F}$ & 0.9 \\
\hline
\end{tabular}


Table II. - Specifications of the PV

\begin{tabular}{|l|c|}
\hline Parameter & Value \\
\hline Type of modules & Polycrystalline silicon $(\mathrm{c}-\mathrm{Si})$ \\
\hline Dimensions $(\mathrm{m})$ & $1.64 \mathrm{X} 0.992 \mathrm{X} 0.04$ \\
\hline Nominal peak power & $250 \mathrm{~W}+3 \%$ \\
\hline Maximum power voltage & $30.00 \mathrm{~V}$ \\
\hline Maximum power current & $8.25 \mathrm{~A}$ \\
\hline Short-circuit current & 8.98 \\
\hline Open-circuit voltage & 37.6 \\
\hline Optimized cell efficiency & $17.2 \%$ \\
\hline Operating temperature & $-40^{\circ} \mathrm{C}$ to $+90^{\circ} \mathrm{C}$ \\
\hline Maximum system voltage & $1000 \mathrm{~V} \mathrm{DC}$ \\
\hline $\begin{array}{l}\text { Power temperature } \\
\text { coefficient }\end{array}$ & $-(0.5 \pm 0.05) \% / \mathrm{K}$ \\
\hline
\end{tabular}

If there is a surplus power production from the PV, then it can be sent back to the grid (feed-in tariffs) when the farm is connected to the grid system. If the farm is isolated then a battery can be utilized to store the excess power or a water storage tank can be used.

\section{Economic Analysis}

For the economic analysis the following equation is used to find Present Value of Cost (PVC) for the PV system:

$$
P V C=I C+(A \times P W F)-s\left(\frac{1}{1+r}\right)^{n}
$$

where IC is the initial cost of the PV system including, civil works, transportation, installation and the cables connection which is US $\$ 17,500$ [16], $A$ is the operation and maintenance cost which is assumed to be $2 \%$ of initial cost. The PWF is the present worth factor, $s$ is the scrap value ( $10 \%$ of the initial cost), $\mathrm{n}$ is the life time of the PV system and $\mathrm{r}$ is the discount rate $(7.55 \%)$. The PWF is found using the following formula:

$$
\mathbf{P W F}=\frac{(1+r)^{\mathrm{n}}-1}{\mathbf{r}(1+r)^{\mathrm{n}}}
$$

The cost of energy is obtained using the following relationship:

$$
\text { Cost }=\frac{\text { PVC }}{\text { kWh } \times \text { PWF }}
$$

where $\mathrm{kWh}$ is the annual energy, which can be calculated using the following equation:

$$
\mathbf{k W h}=\mathbf{P} \times \mathbf{n o} \times 365
$$

where no is the number of operation hours/day. Table III summarizes the results for the different indicators.

Table III. - Results for different indicators

\begin{tabular}{|l|l|}
\hline Indicator & Value \\
\hline PVC $(\$)$ & $21.101 \times 10^{3}$ \\
\hline PWF & 11.1 \\
\hline Energy Cost $(\$ / \mathrm{kWh})$ & 0.17 \\
\hline
\end{tabular}

The average cost for providing electrical connection to the farm from the distribution network is around 1,300 OMR or US \$ 3250 (including labor cost, cable cost, connection box and any administrative work). The cost of extending the public distribution network to the farm can be determined according to the data available from Distribution Company [17]. The cost is found to be around $8,000 \quad \mathrm{OMR} / \mathrm{km}$ (US \$ 20,000) if overhead transmission lines are used. In case of using underground cable the cost will increase. Thus, the cost of PV system is less than the cost of extending the grid network, even if the grid is only $1 \mathrm{~km}$ away from the farm.

\section{Conclusions}

In this paper a PV water pumping system for Oman climate has been designed. A case study for a small farm in Saham was selected and discussed. A well-designed PV pumping system is attractive solution for Oman climate based on economic analysis comparison between the conventional pumping systems connected to grid and the proposed PV system. The result of this work should encourage the government for wide installation of PV pumping system to keep our environment clean and healthy.

\section{References}

[1] A.H. Al-Badi, M. H. Al-Badi, A.M. Al-Lawati, and A.S. Malik, "Economic Perspective for PV Electricity in Oman" Energy, Vol. 36, No.1, pp. 226-232, 2011.

[2] A.H. Al-Badi, "Hybrid (Solar and Wind) Energy System For Al Hallaniyat Island Electrification", International Journal of Sustainable Energy, Vol. 30, No. 4, pp. 212 222, 2011.

[3] A.H. Al-Badi, "Wind Power Potential in Oman", International Journal of Sustainable Energy, Vol. 30, No.2, pp. 110-118, 2011.

[4] A. H. Al-Badi, "Pre-Feasibility Study of Stand-Alone Hybrid Energy Systems for Applications in Eco-Houses", International Journal of Sustainable Engineering, Vol. 6, No. 1, Feb 11, 2013.

[5] A.H. Al-Badi, A. S. Malik, and A. Gastli "Sustainable Energy Usage in Oman - Opportunities and Barriers" Renewable and Sustainable Energy Reviews, Vol. 15, pp. 3780-3788, 2011.

[6] H. Kazem, A. Al-Waeli, A. Al-Kabi, and A. Al-Mamari," Technoeconomical Assessment of Optimum Design for Photovoltaic Water Pumping System for Rural Area in Oman", International Journal of Photoenergy, Volume 2015, http://dx.doi.org/10.1155/2015/514624.

[7] A. G. Bhave, "Potential for solar water-pumping systems in India”, Applied Energy 1994;48:197-200.

[8] C. Kelley, E. Gilbertson, A. Sheikh, D. Steven, S. Dubowsky," On the feasibility of solar-powered irrigation", Renewable and Sustainable Energy Reviews 2010;14:2669-82.

[9] M. Al-Smairan, "Application of photovoltaic array for pumping water as an alternative to diesel engines in Jordan 
Badia, Tall Hassan station: Case study,", Renewable and Sustainable Energy Reviews 16 (2012) 4500-4507

[10] S. Ould-Amrouche, D. Rekioua, A. Hamidat, "Modelling photovoltaic water pumping systems and evaluation of their $\mathrm{CO} 2$ emissions mitigation potential", Applied Energy 87 (2010) 3451-3459

[11] A.A. Ghoneim, "Design optimization of photovoltaic powered water pumping systems" Energy Conversion and Management 47 (2006) 1449-1463

[12] Kala Meah, Sadrul Ula, Steven Barrett, "Solar photovoltaic water pumping-opportunities and challenges", Renewable and Sustainable Energy Reviews, 12 (2008) 1162-1175

[13] Chueco-Fernandez Francisco J, Bayod-Rujula Angel A. 'Power supply for pumping systems in northern Chile : photovoltaic as alternative to grid extension and diesel engines. Energy2010;35:2909-21.

[14] Khatib T. Design of photovoltaic water pumping systems at minimum cost for Palestine: a review. Journal of Applied Sciences 2010;10:2773-84.

[15] New York State, Energy Research and Development Authority. Guide to solar powered water pumping systems in New York State. Available from:/water.epa.gov/infrastructure/sustain/2005_1_27_publi cation_solarpumpingguide.pdfS; 2012[online].

[16] Nafath Renewable Energy L.L.C, C.R: 1185554, info@nafath-oman.com

[17] Muscat Electricity Distribution Company 